\title{
Modos de agir para resolução de conflitos na atenção primária
}

\author{
Juliana Marin ${ }^{1}$, Carlos Dimas Martins Ribeiro ${ }^{1}$ \\ 1. Universidade Federal Fluminense, Niterói/RJ, Brasil.
}

\section{Resumo}

O objetivo deste estudo é analisar modos de agir de profissionais da Estratégia Saúde da Família na resolução de conflitos bioéticos, tomando como fundamento a teoria do agir comunicativo e a ética do discurso. Foi realizada pesquisa qualitativa com uma equipe de saúde da família, com observação, entrevistas e grupo focal. Os resultados mostram que, diante de conflitos, alguns profissionais agem visando o êxito pessoal, o que deixa o conflito sem solução, latente, fragmentando a equipe. Outros, no entanto, buscam o entendimento por meio do agir comunicativo, visando o êxito coletivo, que se traduz no cuidado do paciente. Quando não são resolvidos entre os intervenientes, os conflitos são levados a reuniões que estimulam o diálogo.

Palavras-chave: Atenção primária à saúde. Estratégia saúde da família. Equipe de assistência ao paciente. Bioética. Ética.

\section{Resumen}

\section{Formas de actuar para la resolución de conflictos en atención primaria}

El objetivo de este estudio es analizar los modos de actuar de profesionales para resolución de conflictos bioéticos con otros profesionales de Estrategia de Salud Familiar, teniendo como fundamento la teoría de la acción comunicativa y la ética del discurso. La investigación cualitativa se realizó con un equipo de salud de la familia, con observación, entrevistas y grupo focal. Los resultados muestran que, frente a los conflictos, algunos profesionales actúan hacia el éxito personal, lo que deja el conflicto sin resolver, latente, fragmentando el equipo. Mediante del actuar comunicativo otros profesionales buscan un entendimiento y un acuerdo para el éxito colectivo que se traduce en el cuidado del paciente. Cuando no se resuelven entre los actores, los conflictos se llevan a reuniones que estimulan el diálogo.

Palabras clave: Atenção primária à saúde. Estratégia saúde da família. Equipe de assistência ao paciente. Bioética. Ética.

\begin{abstract}
\section{Ways of acting in conflict resolution in primary health care}

This study examines professionals' ways of acting in the resolution of bioethical conflicts with other professionals in Family Health Strategy teams, based on the Theory of Communicative Action and on Discourse Ethics. For this, a qualitative research was carried out involving observation, interviews and focus group. Faced with a bioethical conflict, some professionals act oriented towards individual success, which allows the conflict to remain latent, thus hindering primary care provision and causing a negative impact on team cohesion. Other professionals, however, use communicative action to seek understandings and agreements aiming at collective success in patient care. Conflicts not resolved between the actors are discussed in team meetings or general meetings, which stimulate team members to engage in communicative action for conflict resolution.
\end{abstract}

Keywords: Primary health care. Family health strategy. Patient care team. Bioethics. Ethics. 
O trabalho na Estratégia Saúde da Família (ESF) estrutura-se por meio de uma equipe interdisciplinar, composta de profissionais com diferentes práticas e saberes técnicos, que oferta ações complementares visando um mesmo objetivo: o cuidado do paciente. Quando esse objetivo é compartilhado entre seus membros, a equipe se fortalece e se torna eficaz ${ }^{1}$.

O cuidado na ESF é entendido como o reconhecimento das demandas do paciente e a oferta das ações necessárias para atendê-las, por meio da articulação de práticas e saberes da equipe. Nesse sentido, o cuidado ganha materialidade não apenas no modo como o profissional trata o paciente, mas também na relação entre os profissionais. Na ESF, portanto, a atenção integral deve observar o imperativo ético de que toda demanda, necessidade de saúde ou sofrimento devem ser acolhidos ${ }^{2}$. Isso exige uma atitude proativa dos profissionais, que devem estar prontos para dar uma resposta ao paciente, seja por meio de orientações ou de atendimento clínico ${ }^{3}$.

O cuidado ainda se apoia em dimensões objetivas fundamentais, como a disponibilidade de serviços e insumos e os mecanismos de regulação. No entanto, apesar de essenciais, esses aspectos não serão objeto da presente pesquisa. O foco aqui recai sobre a necessária interação entre profissionais como forma de estabelecer o processo de trabalho. $O$ cuidado que orienta esse processo deve orientar também a interação interprofissional ${ }^{4}$.

Tal interação é desfigurada quando se age em detrimento de objetivos coletivos, visando apenas êxitos individuais. Quando isso ocorre, surgem problemas e conflitos bioéticos que desagregam as pessoas envolvidas ${ }^{5}$. Assim, os modos de agir dos profissionais podem contribuir para a resolução, manutenção ou agravamento de situações problemáticas.

Considerando esse quadro, o presente estudo procura compreender, com base na ética descritiva, como profissionais agem diante de conflitos ${ }^{6,7}$, comparando seus modos de agir com teorias éticas e as condutas que elas propõem como soluções para tais conflitos ${ }^{8}$. Assim, buscou-se analisar a ação dos profissionais a partir de suas convicções morais, ou seja, o que acreditam ser correto, em confronto com marcos teóricos como o da bioética, campo da ética aplicada em que a função normativa e a descritiva são indissociáveis ${ }^{9}$. A bioética contribui para a resolução dos problemas causadores de conflitos de acordo com a teoria ética que Ihe servirá de padrão de referência ${ }^{10}$.
Para Habermas ${ }^{5}$, conflitos devem ser resolvidos pelo agir comunicativo, por meio do qual os indivíduos interagem com o objetivo de alcançar o entendimento e um acordo. Apesar dos diferentes valores pessoais, deve-se buscar o consenso para fundamentar normas que orientem a ação, em um processo recíproco de convencimento, resultado da cooperação e do diálogo transversal, não cooptado por um saber dominante ${ }^{3}$. Portanto, o agir comunicativo visa o entendimento intersubjetivo por meio de diálogo que considera os interesses coletivos a fim de estabelecer consensualmente uma regra de ação que norteie os indivíduos ${ }^{11}$. Assim, os sujeitos chegam a um acordo pela harmonização de seus interesses individuais, resolvendo conflitos interpessoais de forma equânime, isenta de coerção e imposição ${ }^{12}$.

No agir comunicativo, mediante atos de fala, os intervenientes erguem pretensões de validez considerando as condições de ação ${ }^{11}$. $\mathrm{O}$ ato de fala tem caráter "realizativo", e por esse motivo a pretensão de validez pode ser criticada, corrigida e reconhecida intersubjetivamente por meio de boas razões ${ }^{13}$. Esses atos de fala são constatativos, regulativos e expressivos. Por meio deles, os indivíduos erguem pretensões de verdade, justiça, correção normativa, veracidade ou sinceridade ${ }^{11}$.

Uma proposição é verdadeira - ou seja, o que um indivíduo diz é de fato verdade - quando se cumprem as condições de existência da proposição. Um enunciado é correto em relação com o contexto normativo vigente. Nesse sentido, a norma proferida deve ser legítima no contexto dos indivíduos. E, por fim, um enunciado é sincero quando a proposição coincide realmente com o que a pessoa pensa ${ }^{12}$. Já na ética do discurso os participantes se veem envolvidos nas negociações sobre a validez do enunciado ${ }^{11}$ e devem apresentar normas que corporifiquem interesses comuns, por meio de uma troca de perspectivas entre todos os envolvidos ${ }^{14}$.

Tendo como fundamento a teoria do agir comunicativo e a ética do discurso, o objetivo deste estudo é analisar os modos de agir de uma equipe da ESF na resolução de conflitos bioéticos.

\section{Método}

Participou deste estudo uma equipe de saúde da família de Niterói/RJ, escolhida por ser uma das equipes da cidade que permanecem há mais tempo com a mesma formação. A equipe é composta por 
um médico, um enfermeiro, um dentista, um auxiliar de saúde bucal, um técnico de enfermagem e dois agentes comunitários de saúde. Todos eles aceitaram participar dessa pesquisa. O critério de tempo de trabalho em conjunto foi estabelecido a fim de que ficasse evidente um número maior de problemas e conflitos bioéticos, com expressiva complexidade, vivenciados pelos profissionais.

A unidade de saúde em que a equipe estudada está inserida é composta por mais três equipes todas com um enfermeiro, um técnico de enfermagem, dois agentes comunitários de saúde, um médico, um dentista e um auxiliar de saúde bucal -, totalizando 24 profissionais, pois um dentista e um auxiliar de saúde bucal atuam em duas equipes, estabelecendo-se, portanto, a relação de uma equipe de saúde bucal (dentista e auxiliar de saúde bucal) para duas equipes de saúde da família (médico, enfermeiro, técnico de enfermagem e agente comunitário de saúde.

A inclusão de apenas uma equipe da unidade se justifica pela premissa metodológica de que os membros de um grupo são produto de condições objetivas semelhantes, o que possibilita, apesar da particularidade dos relatos, a vocalização de problemas e conflitos bioéticos vivenciados também por outras equipes ${ }^{15}$. A opção também visou a imersão na equipe a fim de obter dados qualitativos em profundidade. Para isso, a pesquisa seguiu as etapas de observação não participante, entrevistas semiestruturadas e grupo focal.

Na primeira etapa, buscou-se aproximação com a equipe por meio da observação dos profissionais em seu ambiente de trabalho, em meio a suas realidades práticas, individuais e interativas. O acompanhamento ocorreu em dias alternados da semana, totalizando aproximadamente 164 horas. Para essa etapa, foi elaborado um roteiro de observação, e anotações sobre os modos de agir dos profissionais foram feitas em um diário de campo.

Uma dificuldade apresentada durante essa etapa foi certa resistência de alguns profissionais, percebida pela pesquisadora na distância que mantinham e pela indiferença expressa até no cumprimento. Apesar do esclarecimento sobre os objetivos da pesquisa, realizado individualmente com cada profissional, a razão dessa resistência pode ter sido a sensação de estar sendo avaliado. Isso fez que a maioria dos profissionais, durante a observação na unidade, evitasse a pesquisadora, passando a maior parte do tempo em salas de atendimento, o que dificultou a observação da interação entre a equipe. Em contrapartida, as visitas domiciliares foram os momentos mais propícios para estabelecer relações de confiança, em razão das oportunidades de aproximação durante o deslocamento pelo território. A observação prévia ajudou a realizar as entrevistas e o grupo focal, tanto por ter permitido que o roteiro de perguntas fosse elaborado com base na realidade da equipe, quanto por ter estabelecido vínculos entre a pesquisadora e os profissionais.

Após a observação, todos os profissionais da equipe foram entrevistados com auxílio de um roteiro semiestruturado. A proposta era provocar a reflexão dos participantes, para que verbalizassem as suas impressões e o modo como costumam se comportar diante de conflitos bioéticos. As entrevistas, que juntas totalizaram aproximadamente oito horas e meia, foram realizadas e gravadas na própria unidade de saúde.

Na sequência, o grupo focal contou com a participação de toda a equipe, com exceção do dentista, que foi transferido para a assistência de outro território no mesmo período do encontro. O grupo focal foi filmado, o que deu à pesquisadora liberdade para exercer a função de mediadora com total atenção, sem se preocupar em captar no momento todas as peculiaridades do encontro. 0 diálogo durou aproximadamente 1 hora e 28 minutos. O clima foi de descontração, e os profissionais expuseram suas opiniões sem demonstrar inibição com a presença de colegas e da pesquisadora.

Todas as gravações foram transcritas literalmente pela pesquisadora. Os dados foram organizados em categorias de análise que se referem aos modos de agir adotados na resolução de conflitos. A partir dessas categorias, iniciou-se a interpretação dos discursos e a inferência de seus significa$\operatorname{dos}^{16}$. A fim de minimizar o risco de identificação, atribuiu-se a cada participante um número, de 1 a 7 , acompanhado por um algarismo romano que se refere ao nível de escolaridade: I para profissionais de nível superior (enfermeiro, médico e dentista) e II para profissionais de nível técnico, médio ou fundamental (agentes comunitários de saúde, auxiliar de saúde bucal e técnico de enfermagem).

\section{Resultados e discussão}

Neste estudo, considera-se que os conflitos entre profissionais provêm de problemas bioéticos que emergem do trabalho. Alguns profissionais, 
diante de tais conflitos, mesmo conscientes da importância do diálogo para o êxito coletivo, adotam determinados modos de agir que podem intensificar o conflito ou até causar outros problemas. A profissional 1I, por exemplo, diz adotar como regra o isolamento, "para esquecer", pois não gosta de lidar com conflitos: "Olha... Eu prefiro não conversar muito. (...) Não gosto de lidar com qualquer conflito, eu sou do tipo que me isolo, aí fico chateada, aí passa uns dois, três dias, pronto, passou, já esqueci".

Ante qualquer conflito, bioético ou não, esse foi o modo de agir mais adotado pelos profissionais resultado que pode ter sido influenciado pela observação, pois, em situações potencialmente conflituosas, os participantes buscavam se afastar da pesquisadora. Assim, aspectos passíveis de apreensão pela observação não puderam ser trabalhados com o devido aprofundamento, em razão do distanciamento mantido pelos profissionais na maior parte do tempo.

Já o participante 5II adota como norma informar o responsável pela equipe, buscando se isentar da resolução. Pode-se deduzir que, por acreditar que suas ações não foram a causa do conflito, esse profissional considera o outro colega, envolvido na relação conflituosa no papel de "oponente", como digno de repressão: "Se for um colega de trabalho (...) você vira as costas e vai procurar a quem falar, [que] é o enfermeiro responsável: 'aconteceu isso assim, assim"'.

Nos dois casos citados, os profissionais visam o que é melhor para eles e com isso reduzem o conflito moral a algo que pode ser resolvido sem o envolvimento do outro, de modo a controlar a situação, condicionando a resolução do problema à inexistência de interação. No entanto, a consequência desses modos de agir é deixar o conflito latente. Como não houve entendimento entre os intervenientes, a ação que desencadeou a divergência pode se repetir. Além disso, os envolvidos podem guardar certo rancor, especialmente no caso do profissional exposto para o responsável da equipe.

Um terceiro modo de agir é apontado por 7I, que procura convencer seu oponente de que ele está errado, ou seja, busca um acordo imposto. Nessa situação, presume-se uma influência velada sobre o colega, que desiste de argumentar por medo de uma possível punição: "Errada ou certa eu tento convencer, eu tento convencer, eu aposto todos os meus pontos e argumentos (...) Eu consigo fazer a pessoa desistir" (7I). Esse modo de agir pode tanto tornar o conflito latente como criar outras divergências entre os intervenientes. Ademais, a postura não corresponde ao que se espera de profissionais de saúde, pois contraria a dimensão moral do trabalho em conjunto e, por consequência, pode fragmentar a equipe e prejudicar a produção do cuidado.

Já os participantes 2II e 4I optam por explicitar suas escolhas conforme o comportamento do outro, a depender da maior ou menor capacidade de diálogo e entendimento do oponente. Assim, seu modo de agir é dependente do modo de agir adotado pelo outro:

"Conversando com ele, dependendo da pessoa eu converso, se a pessoa conseguir falar, conseguir entender, eu converso. Se a pessoa não consegue falar, não consegue entender, eu não converso. (...) Vai desgastar à toa. Não vai resolver nada, então não precisa nem falar. (...) Tudo o que você falar vai estar errado. Ela não é, ela não fez, não falou, não aconteceu" (4I).

Por fim, 3ll e 6II procuram resolver o problema por meio do diálogo e do entendimento: "É o diálogo mesmo, se não tiver diálogo... É conversa, eu não posso impor, eu não posso brigar por conta disso. Diálogo (...) pra gente lançar o nosso pensamento e chegar a um objetivo só" (3II).

As diferentes falas mostram que alguns profissionais tendem a adotar suas próprias estratégias de enfrentamento, percebidas pelos demais membros da equipe como alienação ou descompromisso ${ }^{17}$. Essas estratégias prevalecem sobre o agir comunicativo, pois a resolução dos conflitos pelo diálogo requer lidar com contradições, diferenças e expectativas. Outros obstáculos que podem dificultar ou impedir a resolução dos problemas são a falta de tempo provocada pelo excesso de trabaIho, a falta de motivação para lidar com conflitos e o medo de que o enfrentamento das divergências cause desconforto emocional ${ }^{18}$.

A partir da identificação de problemas éticos, como a procrastinação, a fofoca e o absenteísmo, e dos modos de agir que os intervenientes adotam para resolver conflitos, foi possível verificar que, quando não se adota o agir comunicativo, as divergências permanecem latentes. Essa postura não contribui para o êxito da equipe, e não basta que apenas alguns profissionais valorizem o diálogo. $O$ conflito bioético fragmenta a equipe se não há articulação entre os profissionais e responsabilidade pelo cuidado do paciente. 
A responsabilidade é um dos elementos que caracterizam a produção do cuidado na ESF, junto com o compromisso, a integralidade, o acolhimento e a escuta, que são, em grande medida, ideais éticos. Portanto, o conceito de equipe deve se ligar a esses ideais da ESF, especialmente no que se refere à responsabilidade e ao compromisso com o usuário.

Mudar paradigmas nos serviços e nas relações interpessoais implica transformar práticas e aderir a novas propostas ${ }^{19}$. Os profissionais não escolhem trabalhar juntos, mas precisam aprender a lidar com as dinâmicas relacionais e os processos de interação com o outro ${ }^{20-22}$. $\mathrm{Na}$ verdade, é necessário que a equipe analise seu modo de operar para reconhecer suas capacidades, fragilidades e potências para mudanças ${ }^{23}$. Um grupo de profissionais só se torna de fato uma equipe quando há responsabilidade em relação a um objetivo comum, que é a produção do cuidado - que depende, por sua vez, de valores assumidos na relação com o paciente e com os colegas de trabalho.

Quando não é resolvido, o conflito é levado para a reunião geral, entre as quatro equipes, ou para a reunião de equipe, a depender dos envolvidos. Semanalmente, às quartas-feiras, no período da tarde, a unidade fecha para atendimento e ocorre uma reunião com os profissionais das quatro equipes. Uma vez a cada três meses, em média, há uma reunião entre os membros da equipe estudada. O longo intervalo entre os encontros é justificado pela falta de tempo em razão da demanda de trabaIho. Sobre essas reuniões, relatam os participantes:

\begin{abstract}
"Aí, se tiver um problema, vamos supor, entre eu $e$ outro profissional do outro setor [equipe], se eu não tiver muita afinidade com ele, se eu não tiver muita abertura, eu vou falar na reunião de equipe, eu não vou falar pra ele. Eu vou falar pra ele, mas na reunião de equipe" (4I).
\end{abstract}

"Não conseguiu ser [resolvido] só entre as duas pessoas, então já que ali entre as duas não estava sendo feito esse acordo, então foi colocado no geral [na reunião de equipes]" (5II).

"Até para poder dar exemplo mesmo. Nós, todos nós temos defeitos, [e as reuniões servem para] nos consertarmos. De repente [é] dentro da equipe, de repente não. Sempre acontece, é um processo de trabalho. É o nosso processo de trabalho, de um modo geral é nosso processo de trabalho. Ali dentro tem conflitos" (6II).
Problemas e conflitos são indissociáveis do trabalho em equipe. No entanto, eles podem comprometer o alcance dos objetivos coletivos ou se tornar uma possibilidade de crescimento, se forem trabaIhados ${ }^{24}$. Nas reuniões entre as equipes, os profissionais buscam o entendimento por meio do diálogo, abrangendo todos os indivíduos que reconhecem o acordo estabelecido como um "exemplo", ou seja, uma norma orientadora das ações. O mesmo ocorre nas reuniões entre uma mesma equipe.

Foi possível observar que profissionais que geralmente assumem estratégias de ação não comunicativas, nas reuniões de equipe ou entre equipes, tendem a adotar o agir comunicativo. Isso talvez ocorra em razão do contexto, com um número de intervenientes ampliado, o que leva os profissionais a lançar pretensões de validez para justificar a própria ação, inibindo posturas orientadas ao sucesso individual. Portanto, as reuniões tornam mais homogêneo o modo de agir na resolução de conflitos.

Diante de um conflito causado, por exemplo, pela procrastinação, o indivíduo que busca o entendimento para estabelecer uma norma de ação válida deve levantar explicitamente três pretensões de validade: a pretensão de verdade, ou seja, o que ele diz é verdadeiro ("você está procrastinando"); a pretensão normativa, que condiz com a norma vigente ("não se deve procrastinar"); e a pretensão de sinceridade, que traduz a coerência entre o que ele fala e o que realmente pensa. O ouvinte pode: 1) concordar com as pretensões de validade, firmando um acordo; 2) discordar e questionar as pretensões levantadas pelo falante; ou 3) discordar, mas não questionar as pretensões.

No primeiro caso, o entendimento e uma norma consensual orientadora das ações são estabelecidos. $O$ conflito entre os intervenientes e o problema que o originou são resolvidos, pois se entende que, com o acordo, o indivíduo deixará de procrastinar. $\mathrm{O}$ ouvinte aceita a pretensão de verdade levantada (pois reconhece que, de fato, está procrastinando), a pretensão normativa (não se deve procrastinar) e a pretensão de sinceridade (o falante não procrastina).

No segundo caso, o ouvinte questiona a pretensão de verdade ou normativa, sendo necessária a argumentação do falante para justificar a pretensão. De acordo com Habermas ${ }^{14}$, nessa situação, ocorre a passagem do agir comunicativo para o discurso, pois, a partir do questionamento, o falante busca legitimar as pretensões de verdade e validez normativa por meio da argumentação, que se estabelece 
na troca intersubjetiva para avaliar informações e motivos $^{3}$. Nesse momento, os interlocutores têm de estar dispostos a atender às exigências de cooperar uns com os outros na busca de razões aceitáveis para os outros; e, mais ainda, têm de estar dispostos a deixar-se afetar e motivar, em suas decisões ${ }^{25}$.

A pretensão de sinceridade não é interior ao discurso, mas se refere à consistência do comportamento dos indivíduos, pois se parte do pressuposto de que deve haver coerência entre fala, pensamento e conduta ${ }^{11}$. Já as pretensões de verdade são contestadas ou problematizadas por meio de discursos teóricos, enquanto as pretensões de correção normativa se referem a discursos práticos ${ }^{26}$.

No discurso teórico, busca-se redefinir ou corroborar afirmações sobre fatos ${ }^{27}$. No discurso prático, os enunciados são apreciados à luz de razões ${ }^{14}$, e a validade das normas é questionada de acordo com o arranjo social dos indivíduos ${ }^{27}$. Nesse caso, os intervenientes buscam a compreensão sobre um interesse comum, para pactuar normas e chegar a um equilíbrio ${ }^{11}$. Logo, o consenso é gerado pelo convencimento mútuo, pela consciência de que é interesse de cada um e de todos agir de tal modo ${ }^{11}$. Essa conduta cria um compromisso entre os agentes, pois a norma foi fundamentada e justificada coletivamente ${ }^{28}$.

Quando as pretensões de validade são questionadas, os indivíduos podem chegar ou não a um acordo. No terceiro caso, o indivíduo discorda, porém não questiona as pretensões. Ele se cala e oculta o que pensa a respeito da matéria em discussão, sem levantar qualquer outra pretensão de verdade. Quando age assim, o ouvinte está simulando e comportando-se estrategicamente ${ }^{29}$.

No trecho do grupo focal destacado a seguir, os profissionais abordam outro problema relacionado à comunicação, comum quando se trabalha em equipe, a fofoca:

"Vocês disseram que tentam resolver [o conflito] no diálogo, mas vocês conseguem chegar num acordo?" (pesquisadora).

"A gente chega num consenso... Assim, cada um [sabe], eu sei que é errado fazer fofoca" (7I).

"Cabe a cada pessoa parar de fazer" (4I).

“Ou não, entendeu?" (7I).

“Então não há esse consenso?” (pesquisadora).

"Há. A pessoa vai dizer: 'sim, nós vamos parar de fazer', mas não me garante se ela não vai fazer, ela não dá garantias que realmente ela não vai falar" (7I).

"Eu chego para $7 \mathrm{l}$ falando que está bem, mas às vezes não está, então tem que ser verdadeiro" (2II).

Em situações de ação estratégica dissimulada, pelo menos um dos participantes se conduz pela realização de seus fins particulares, mas faz com que os demais acreditem que todos estão cumprindo os pressupostos da ação comunicativa ${ }^{12}$. Esse modo de agir de acordo com os próprios interesses, sem adotar a norma estabelecida coletivamente, acaba gerando outros conflitos:

"Nossa reunião é na quarta, aí na quinta-feira fica todo mundo bem. Houve uma mudança. Aí, na sexta... [risos]" (2II).

"Volta tudo ao normal" (5II).

"Volta ao normal [risos]" (6II).

"Aí como não é resolvido, é como se fosse um vírus que se espalha, de repente. (...) Eu faço uma coisa que é reprovável (...): 'pô, se 211 fez, eu vou fazer', e acaba se espalhando como um vírus" (2II).

"Fica aquela pedra no meio do caminho que vai impedindo a gente de andar" (2II).

Nas reuniões, os indivíduos buscam o entendimento para estabelecer uma norma de ação, mas nem sempre alcançam esse objetivo, pois há indivíduos que agem orientados pelo próprio êxito, em detrimento do êxito coletivo. Isso revela descompromisso e falta de solidariedade com os outros profissionais, com prejuízo para o cuidado do paciente. De fato, sem os preceitos do agir comunicativo, não é possível alcançar um acordo, pois a ética discursiva, que oferece o discurso prático para estabelecer uma norma, fundamenta o conteúdo de uma moral do respeito sem distinções, do compromisso e da solidariedade ${ }^{30}$.

Ainda que nem todos se pautem pelo agir comunicativo, a maioria dos participantes da pesquisa concorda que as reuniões são importantes para resolver conflitos interprofissionais. Trata-se de ocasiões fundamentais para promover a comunicação, a cooperação e o senso de compromisso e de corresponsabilidade em torno de objetivos comuns ${ }^{1,31}$. Portanto, além de estimular o agir comunicativo para resolução de conflitos morais, as reuniões amplificam valores que facilitam o entendimento e o acordo. Esses 
encontros são importantes para a efetividade do trabalho da equipe ${ }^{32}$, ajudando a resolver conflitos e a promover relações interpessoais positivas ${ }^{33}$.

Entretanto, quanto às reuniões entre equipes, que acontecem com mais frequência, semanalmente, nem todos os profissionais entendem que a participação faz parte do trabalho. Muitos, por exemplo, aproveitam o período para resolver questões pessoais fora da unidade. Além disso, a abordagem de temáticas das quatro equipes, com 24 profissionais envolvidos, favorece a desorganização. Com isso, muitas vezes a reunião se descaracteriza, e sua proposta acaba sendo deturpada: "A gente senta, aí começa a lavação de roupa suja, é uma confusão" (3II); "Toda quarta-feira (...) é nossa reunião interna, que é a lavação de roupa suja" (5II).

As reuniões deveriam ser espaços produtivos de planejamento, organização e avaliação dos processos de trabalho, bem como um momento para reconhecer e resolver conflitos, sejam eles bioéticos ou não. Pela grande quantidade de pessoas, os encontros entre equipes acabam não cumprindo esses objetivos. As reuniões de equipe, por outro lado, parecem funcionar melhor: "A gente tem que ter mais reunião de equipe, para a gente poder falar. (...) A gente tem que ter reunião para a gente poder pontuar as coisas que às vezes atrapalham o andamento do trabalho da equipe. (...) Para ter essa conversa, para a gente lançar o nosso pensamento $e$ chegar a um objetivo só" (3II). No entanto, é preciso estar atento para que a interação não se restrinja às reuniões, o que representaria um obstáculo para a realização plena e eficiente do trabalho ${ }^{34,35}$.

Quarenta e dois dias depois do grupo focal, em conversa informal na unidade, o enfermeiro responsável pela equipe relatou que alguns participantes vinham se mostrando mais flexíveis em relação aos outros profissionais. Ter flexibilidade, perceptiva e comportamental, de acordo com Moscovici, significa procurar ver vários ângulos ou aspectos da mesma situação e atuar de forma diferenciada, não rotineira, experimentando novas condutas percebidas como alternativas de ação ${ }^{36}$. Quando questionado sobre o motivo da mudança, o enfermeiro atribuiu a melhora ao grupo focal.

O presente estudo não foi projetado para ser uma pesquisa-ação, mas o grupo focal deu uma oportunidade aos profissionais para dialogar sobre problemas e conflitos que emergem no trabalho. Esse diálogo pode ter levado ao autodiagnóstico dos modos de agir. Um mesmo processo de reflexão deveria ser fomentado pelas reuniões de equipe.

\section{Considerações finais}

Alguns modos de agir impõem barreiras para a resolução de conflitos e por vezes até catalisam outros problemas, o que pode fragmentar as relações entre profissionais, com prejuízos à produção do cuidado. Ao contrário, o agir comunicativo, visando o êxito coletivo e a harmonização de interesses individuais, amplia as possibilidades de coordenar as ações com base no entendimento e no comum acordo. Quando são estabelecidas coletivamente, normas de ação passam a orientar condutas de acordo com o interesse comum. Consequentemente, torna-se mais fácil resolver não apenas o conflito, mas também os problemas que o originaram. Por esse motivo, o agir comunicativo deve ser um dos atributos das equipes de saúde da família.

A reunião é um espaço privilegiado, que estimula o agir comunicativo e favorece a resolução de problemas e conflitos. Entretanto, nem sempre é possível estabelecer normas morais por meio do diálogo, principalmente quando profissionais agem estrategicamente de forma dissimulada. Outro fator que prejudica a resolução de problemas e conflitos é a desorganização e desvalorização desses momentos de comunicação, bem como o longo período entre um encontro e outro no caso das reuniões de equipe. Além de perderem uma oportunidade para resolver conflitos, os profissionais que faltam às reuniões desperdiçam um momento em que podem se reconhecer como parte da equipe. A falta desse reconhecimento enfraquece o compromisso e a solidariedade, dificultando o entendimento e o acordo. Para buscar reverter o cenário supracitado, é necessário o revezamento semanal de reuniões entre equipes e de equipe e a conscientização dos profissionais sobre a importância desses encontros, que integram o processo de trabalho e devem ser conduzidos com critérios.

$\mathrm{O}$ agir comunicativo e a ética do discurso buscam universalizar condutas mediante o entendimento e a formulação consensual de normas. Dadas as suas características, esses fundamentos teóricos podem ser aplicados em situações práticas e cotidianas de uma equipe de saúde, sobretudo na resolução de conflitos. Entretanto, chegar à intercompreensão e ao acordo por meio do diálogo requer solidariedade e compromisso. É preciso reconhecer a importância do outro na produção do cuidado e buscar sempre o que é melhor e mais justo para a equipe e para o usuário do sistema. 


\section{Referências}

1. Cashman SB, Reidy P, Cody K, Lemay CA. Developing and measuring progress toward collaborative, integrated, interdisciplinar health care teams. J Interprof Care [Internet]. 2004 [acesso 27 jan 2021];18(2):183-96. DOI: 10.1080/13561820410001686936

2. Brasil. Ministério da Saúde. Política Nacional de Atenção Básica [Internet]. Brasília: Ministério da Saúde; 2012 [acesso 27 jan 2021]. p. 19. Disponível: https://bit.ly/33uvipU

3. Guerrero P, Mello ALSF, Andrade SR, Erdmann AL. O acolhimento como boa prática na atenção básica à saúde. Texto Contexto Enferm [Internet]. 2013 [acesso 27 jan 2021];22(1):132-40. Disponível: https://bit.ly/3y1ydVb

4. Atwal A, Caldwell K. Do all health and social care professionals interact equally: a study of interactions in multidisciplinary teams in the United Kingdom. Scand J Caring Sci [Internet]. 2005 [acesso 27 jan 2021];19(3):268-73. DOI: 10.1111/j.1471-6712.2005.00338.x

5. Habermas J. Ética do discurso. Lisboa: Edições 70; 2014.

6. Zoboli ELCP. Bioética e Atenção Básica: um estudo de ética descritiva com enfermeiros e médicos do Programa Saúde da Família [tese] [Internet]. São Paulo (SP): Universidade de São Paulo; 2003 [acesso 27 jan 2021]. Disponível: https://bit.ly/3bhvb5c

7. Beauchamp TL, Childress JF. Princípios de ética biomédica. São Paulo: Loyola; 2011.

8. Rego S, Gomes AP, Siqueira-Batista R. Bioética e humanização como temas transversais na formação médica. Rev Bras Educ Méd [Internet]. 2008 [acesso 27 jan 2021];32(4):482-91. Disponível: https://bit.ly/3uOQx1X

9. Rego S. Contribuições da bioética para a saúde pública. Cad Saúde Pública [Internet]. 2007 [acesso 27 jan 2021]; 23(11):2530-1. Disponível: https://bit.ly/3o4KPWU

10. Schramm FR. Bioética, biossegurança e a questão da interface no controle das práticas da biotecnociência: uma introdução. Rev Redbioét/UNESCO [Internet]. 2010 [acesso 27 jan 2021];1(2):99-110. p. 106. Disponível: https://bit.ly/3y19Qa7

11. Habermas J. Consciência moral e agir comunicativo. Rio de Janeiro: Tempo Brasileiro; 1989.

12. Habermas J. Teoría de la acción comunicativa, I: racionalidad de la acción y racionalización social. Madrid: Taurus; 1999.

13. Conte E, Martini R. Habermas e a educação: aporias sobre a performance. In: Lima CRM, Gómez MNG, editores. Diálogos habermasianos [Internet]. Rio de Janeiro: IBICT; 2010 [acesso 27 jan 2021]. p. 280. Disponível: https://bit.ly/3o4SDbe

14. Habermas J. Verdade e justificação: ensaios filosóficos. São Paulo: Loyola; 2004.

15. Bourdieu P. Esboço de uma teoria da prática. In: Ortiz R, editor. Pierre Bourdieu. São Paulo: Ática; 1983. p. 46-81.

16. Minayo MCS. O desafio do conhecimento: pesquisa qualitativa em saúde. São Paulo: Hucitec; 2010.

17. Cardoso AS, Nascimento MC. Comunicação no Programa Saúde da Família: o agente de saúde como elo integrador entre a equipe e a comunidade. Ciênc Saúde Coletiva [Internet]. 2010 [acesso 27 jan 2021];15(1 Supl):1509-20. p. 1519. DOI: 10.1590/S1413-81232010000700063

18. Brown J, Lewis L, Ellis K, Stewart M, Freeman TR, Kasperski MJ. Conflict on interprofessional primary health care teams - can it be resolved? J. interprof. care. [Internet]. 2011 [acesso 27 jan 2021]; 25:4-10. DOI: $10.3109 / 13561820.2010 .497750$

19. Nascimento DDG, Oliveira MAC. Reflexões sobre as competências profissionais para o processo de trabalho nos Núcleos de Apoio à Saúde da Família. Mundo Saúde [Internet]. 2010 [acesso 27 jan 2021];34(1):92-6. Disponível: https://bit.ly/33voLZd

20. Navarro ASS, Guimarães RLS, Garanhani ML. Trabalho em equipe: o significado atribuído por profissionais da estratégia de saúde da família. REME Rev Min Enferm [Internet]. 2013 [acesso 27 jan 2021];17(1):61-8. DOI: $10.5935 / 1415-2762.20130006$

21. Franco TB, Merhy EE, editores. O reconhecimento de uma produção subjetiva do cuidado. São Paulo: Hucitec; 2013. 
22. Matuda CG, Pinto NRS, Martins CL, Frazão P. Colaboração interprofissional na Estratégia Saúde da Família: implicações para a produção do cuidado e a gestão do trabalho. Ciênc Saúde Coletiva [Internet]. 2015 [acesso 27 jan 2021];20(8):2511-21. DOI: 10.1590/1413-81232015208.11652014

23. Merhy EE, Feuerwerker LCM. Novo olhar sobre as tecnologias de saúde: uma necessidade contemporânea. In: Mandarino ACS, Gomberg E, editores. Leituras de novas tecnologias e saúde. São Cristóvão: Editora UFS; 2009. p. 29-74.

24. Fortuna CM, Mishima SM, Matumoto S, Pereira MJB. O trabalho de equipe no programa de saúde da família: reflexões a partir de conceitos do processo grupal e de grupos operativos. Rev Latinoam Enferm [Internet]. 2005 [acesso 27 jan 2021];13(2):262-8. p. 267. Disponível: https://bit.ly/3feBDvk

25. Habermas J. A ética da discussão e a questão da verdade. São Paulo: Martins Fontes; 2013. p. 15.

26. Rouanet SP. Ética iluminista e ética discursiva. Revista Tempo Brasileiro. 1989;98:23-78.

27. Freitag B. Dialogando com Jürgen Habermas. Rio de Janeiro: Tempo Brasileiro; 2005.

28. Vázquez AS. Ética. Rio de Janeiro: Civilização Brasileira; 2008.

29. Habermas. 1999. p. 41.

30. Habermas J. A inclusão do outro: estudos de teoria política. São Paulo: Loyola; 2002.

31. Sargeant J, Loney E, Murphy G. Effective interprofessional teams: "contact is not enough" to build a team. J Contin Educ Health Prof [Internet]. 2008 [acesso 27 jan 2021];28(4):228-34. DOI: 10.1002/chp.189

32. Nancarrow SA, Booth A, Ariss S, Smith T, Enderby P, Roots A. Ten principles of good interdisciplinary team work. Hum Resour Health [Internet]. 2013 [acesso 27 jan 2021];11. DOI: 10.1186/1478-4491-11-19

33. Xyrichis $\mathrm{A}$, Lowton $\mathrm{K}$. What fosters or prevents interprofessional teamworking in primary and community care? A literature review. Int J Nurs Stud [Internet]. 2008 [acesso 27 jan 2021];45(1):140-53. DOI: 10.1016/ j.ijnurstu.2007.01.015

34. Colomé ICS, Lima MADS, Davis R. Visão de enfermeiras sobre as articulações das ações de saúde entre profissionais de equipes de saúde da família. Rev Esc Enferm USP [Internet]. 2008 [acesso 27 jan 2021];42(2):256-61. Disponível: https://bit.ly/2R7jPKg

35. Zanchett S, Dallacosta FM. Percepção do profissional da saúde sobre a importância do trabalho multiprofissional e interdisciplinar na atenção básica. Rev Interdiscip Estud Saúde [Internet]. 2015 [acesso 27 jan 2021];4(2):145-53. Disponível: https://bit.ly/3ezkhK9

36. Moscovici F. Competência interpessoal no desenvolvimento de gerentes. Rev Adm Emp [Internet]. 1981 [acesso 27 jan 2021];21(2):17-25. p. 17. Disponível: https://bit.ly/3eCwrSw

Juliana Marin - Doutora - jubsmarin@yahoo.com.br

(D) 0000-0001-5306-1294

Carlos Dimas Martins Ribeiro - Doutor - dimasmribeiro@gmail.com

(D) 0000-0002-3838-5239

Correspondência

Juliana Marin - Rua Marquês do Paraná, 303, $4^{\circ}$ andar, Centro

CEP 24030-210. Niterói/RJ, Brasil.

Participação dos autores

Juliana Marin concebeu a pesquisa, coletou e analisou os dados e redigiu o artigo.

Carlos Dimas Martins Ribeiro orientou o estudo e foi responsável pela revisão crítica do artigo.

Recebido: $\quad 5.3 .2020$

Revisado: 30.4 .2021

Aprovado: 4.5 .2021 